$\mathrm{AB} 0524$

HOW DO WE TREAT DRYNESS IN PATIENTS WITH PRIMARY SJÖGREN'S SYNDROME? A NATIONWIDE STUDY IN SPAIN FROM THE SJOGRENSER REGISTRY

M. Fernandez Castro ${ }^{1}$, C. Sanchez-Piedra ${ }^{2}$, J.L. Andreu ${ }^{3}$, V. Martinez Taboada ${ }^{4}$, A. Olive ${ }^{5}$, J. Rosas ${ }^{6}$, on behalf of SJOGRENSER project (GEEAS-SER).

${ }^{1}$ Rheumatology, Hospital Infanta Sofía, Madrid; ${ }^{2}$ Research Unit of the Spanish Society of Rheumatology; ${ }^{3}$ Rheumatology, Hospital Puerta de Hierro

Majadahonda, Madrid; ${ }^{4}$ Rheumatology, Hospital Marques de Valdecilla, Santander, ${ }^{5}$ Rheumatology, Hospital Germans Trias i Pujol, Barcelona;

${ }^{6}$ Rheumatology, Hospital Marina Baixa, Alicante, Spain

Background: Primary Sjögren syndrome (pSS) is a systemic autoimmune disease whose main characteristic is the involvement of the exocrine glandular system. Thus, its most common clinical manifestation is eye and mouth dryness. No therapy has been demonstrated to significantly modify disease course and, currently, evidence-based therapy for pSS is mainly limited to symptomatic drugs for drynes.

Objectives: To describe the dryness treatment in a cohort of primary Sjögren Syndrome patients.

Methods: SJOGRENSER registry is a multicentre descriptive cross-sectional study of pSS patients, fulfilling European/American criteria, from 33 Spanish rheumatology departments. Data were collected by reviewing clinical records and interviewing the patients. Informed consent was obtained and local ethics committees approved the study. Variables were analysed by descriptive statistics using means, medians and ranges. Chi square test was used to compare categorical variables. A $p<0.05$ was considered significant.

Results: Four hundred and thirty seven patients were included (female 95\%; median age 58 years). Ninety four per cent of the patients complained of daily, persistent, troublesome dry eyes for more than 3 months, $92 \%$ had sensation of sand in the eyes, $16 \%$ developed corneal ulcer. Ninety four per cent of the patients complained of dry mouth for more than 3 months and $27 \%$ had dental loss. The most frequent ocular dryness treatments were tear substitutes (96\%), followed by lubricating ophthalmological ointments $(46 \%)$, autologous sera solutions $(14 \%)$, topical corticosteroids (13\%), topical cyclosporine $(6 \%)$. Comparing patients with and without ocular dryness, only pilocarpine and lubricating eye ointment were used significantly with more frequency in symptomatic patients $(p<0.05)$; tear substitutes was used significantly with more frequency in symptomatic patients only in the subgroup of patients that used tear substitutes more than 3 times a day. The most frequent oral dryness treatments were chewing gums or candies without sugar $(65 \%)$, followed by pilocarpine $(56 \%)$, special toothpaste $(22 \%)$, mucolytic agents $(20 \%)$, saliva substitutes $(19 \%)$, lubricating oral gel $(13 \%)$ xylitol $(11 \%)$ and fluoride (11\%). Comparing patients with and without oral dryness, chewing gums or candies without sugar, xylitol and fluoride were not used significantly more frequently in symptomatic patients. In contrast, saliva substitutes, lubricating oral gel, pilocarpine, mucolytic agents and specific toothpaste were used significantly more frequently in symptomatic patients $(p<0.05)$. The median in ESSPRI (Eular Sjögren's Syndrome Patient Reported Index) in SJOGRENSER cohort was 5.3 (p25-p75, 3.67-7). Only topical corticosteroids and pilocarpina were used significantly more frequently in patients with a dryness VAS $>5$ in ESSPRI index.

Conclusions: Despite the high number of symptomatic patients, the use of dryness treatments is limited in pSS patients. Chewing gums or candies without sugar, xylitol and fluoride remain underutilised in this cohort. Despite the dryness VAS score, patients do not seem to use all the symptomatic therapeutic options available.

Disclosure of Interest: None declared

DOI: 10.1136/annrheumdis-2018-eular.4455

\section{AB0525 IDENTIFICATION OF EFFECTIVE PARAMETERS INFORMING THE SELECTION OF INTRAVENOUS CYCLOPHOSPHAMIDE VERSUS MYCOPHENOLATE MOFETIL FOR INDUCTION THERAPY FOR LUPUS NEPHRITIS}

N. Mino, H. Yamashita, K. Motomura, M. Nakahara, K. Suga, A. Yashima, Y. Takahashi, H. Kaneko. Rheumatology, National Center for Global Health and Medicine, Tokyo, Japan

Background: The 2012 EULAR recommendations gave equal weight to intravenous cyclophosphamide (IVCY) and mycophenolate mofetil (MMF) as the induction therapy for class III/IV lupus nephritis (LN). However, there are no effective parameters that could inform the choice the induction therapy (IVCY or MMF) in individual cases.

Objectives: This study examined the patient characteristics that determine the most appropriate treatment for LN: IVCY or MMF.

Methods: We retrospectively examined 29 patients with $\mathrm{LN}$ who received induction therapy with IVCY $(n=16)$ or MMF $(n=13)$ between January 1994 and December 2015. Their baseline characteristics and the complete response (CR) rate at week 24 were analysed. CR was defined as a urine protein:creatinine ratio $<0.5 \mathrm{~g} /$ gCre with normal urine sediment.

Results: At baseline, the time since diagnosis of systemic lupus erythematosus (SLE) was longer in the IVCY group than the MMF group (4.8 $\pm 6.4 \mathrm{vs} .1 .3 \pm 2.5$ years, $p=0.06)$ and the IVCY group had more frequent flares $(1.9 \pm 2.4$ vs. $0.7 \pm 1.1$ times, $\mathrm{p}=0.08$ ); however, the differences were not significant. Moreover, there was no difference in age, sex, complement levels, anti-dsDNA antibody titers, anti-Sm/RNP antibody positivity rates, proteinuria, or rate of abnormality in urine sediment at baseline between the two groups. CR was achieved at week 24 in 11/ 16 patients $(69 \%)$ in the IVCY group and $9 / 13$ patients $(69 \%)$ in the MMF group. Considering the 20 patients who achieved $\mathrm{CR}$ at week 24 , univariate analyses revealed that in addition to a longer time since diagnosis of SLE $(4.5 \pm 6.6 \mathrm{vs}$. 1.0 \pm 1.7 years, $p=0.12$ ) and more frequent flares $(1.9 \pm 2.8 \mathrm{vs}$. $0.6 \pm 1.0$ times, $\mathrm{p}=0.16)$, the anti-RNP antibody positivity rate was higher (OR $8.15 ; \mathrm{p}=0.07)$ in the IVCY group. Furthermore, the positivity rate of anti-RNP antibody differed significantly (OR 12.9; $\mathrm{p}=0.03$ ) in the multivariate analysis.

Abstract AB0525 - Table 1. Univariate analyses of patients with CR at week 24

\begin{tabular}{lccc}
\hline & IVCY $(\mathrm{n}=11)$ & $\operatorname{MMF}(\mathrm{n}=9)$ & $p$ value \\
\hline age (years) & $31.2 \pm 10.9$ & $39.6 \pm 18.8$ & 0.23 \\
sex (male,\%) & 9.1 & 22.2 & $0.57, \mathrm{OR}=2.71$ \\
time since diagnosis of SLE (years) & $4.5 \pm 6.6$ & $1.0 \pm 1.7$ & 0.12 \\
flares (times) & $1.9 \pm 2.8$ & $0.6 \pm 1.0$ & 0.16 \\
complement C3 level (mg/dL) & $48.3 \pm 29.3$ & $47.6 \pm 21.5$ & 0.95 \\
anti-dsDNA antibody (IU/mL) & $161.2 \pm 187.4$ & $128.8 \pm 154.2$ & 0.68 \\
anti-Sm antibody $(\%)$ & 63.6 & 33.3 & $0.37, \mathrm{OR}=3.27$ \\
anti-RNP antibody $(\%)$ & 72.7 & 22.2 & $0.07, \mathrm{OR}=8.15$ \\
\hline
\end{tabular}

Abstract AB0525 - Table 2. Multivariate analyses of patients with $\mathrm{CR}$ at week 24

\begin{tabular}{lcccc}
\hline & \multicolumn{3}{c}{ Model 1 } & \multicolumn{2}{c}{ Model 2 } \\
\cline { 2 - 5 } & OR (95\% Cl) & $p$ value & OR (95\% Cl) & $p$ value \\
\hline age & - & - & $0.9(0.8-1.0)$ & 0.15 \\
sex (female) & - & - & $1.2(0.04-38.8)$ & 0.92 \\
time since diagnosis of SLE & $1.1(0.7-1.7)$ & 0.77 & $1.0(0.6-1.6)$ & 0.91 \\
flares & $1.5(0.5-4.2)$ & 0.44 & $1.7(0.6-4.4)$ & 0.30 \\
anti-RNP antibody & $12.9(1.3-132.3)$ & $0.03^{*}$ & $31.8(1.1-892.9)$ & $0.04^{*}$ \\
\hline
\end{tabular}

Model 1 was adjusted by all of the characteristics which showed $p<0.20$ in the univariate analysis; model 2 was adjusted by age and sex in addition to model 1 .

dsDNA, double strand DNA; anti-Sm antibody, anti-smith antibody; anti-RNP antibody, antiribonucleoprotein antibody; $\mathrm{OR}$, odds ratio; $\mathrm{Cl}$, confidence interval. ( $\left.{ }^{*} \mathrm{p}<0.05\right)$

Conclusions: Although IVCY and MMF are equivalent treatment options for LN IVCY might be more effective for patients with anti-RNP antibody.

\section{REFERENCE:}

[1] George K, Bertsias, et al. Annals of the Rheumatic Diseases 2012;71:1771-1782.

Disclosure of Interest: None declared DOI: 10.1136/annrheumdis-2018-eular.3860

\section{AB0526 IMBALANCE IN ELASTIN-ELASTASE SYTEM LEADING TO CLINICAL MANIFESTATIONS OF SYSTEMIC LUPUS ERYTHEMATOSUS}

O. Emelyanova ${ }^{1}$, O. Rusanova ${ }^{1}$, I. Gontar ${ }^{1}$, L. Maslakova ${ }^{1}$, N. Emelianov ${ }^{2}$ ${ }^{1}$ Federal State Budgetary Institution «Research Institute of Clinical fnd Experimental Rheumatology named after A.B. Zborovsky"; ${ }^{2}$ Federal State Medical Budgetary Institution of Higher Education "Volgograd State Medical University" of the Ministry of Healthcare of the Russion Federation, Volgograd, Russian Federation

Background: It is believed that in systemic lupus erythematosus antibodies induce a disturbance in the elastin-elastase metabolism, which yields altered soluble isoforms followed by triggering of autoimmunity mechanisms, which damage the elastin-containing tissues.

Objectives: Studying antibody formation in the elastin-elastase system in patients with systemic lupus erythematosus (SLE) using magnetocontrollable adsorbents with an immobilised form of corresponding antigen.

Methods: Sera from 30 donors and 65 SLE patients were studied. Antibodies to elastin and elactase were determined using ELISA test and magnetocontrollable adsorbents with an immobilised form of corresponding antigen.

Results: We analysed changes in the content of antibodies to elastin and elastase in patients with SLE of varying severity assessed using SLAM, SLEDA scale, and criteria by V.A. Nasonova. 
The greatest elastin antibody titer was noted in patients with SLE grade III (57.1\%, 4 people), with grade II - in 42.5\% (17 people), and with grade I - in 33.3\% (6 people).

The elastin antibody titer in SLE patients being admitted to hospital was reliably higher than in donors $(p<0.001)$.

An analysis of the findings showed that patients with vascular lesions demonstrated a significant elevation of elastin antibodies $(p<0.05)$.

Besides studying elastin antibodies, we analysed elastase antibodies. Elevated elastase antibodies were revealed in $72.2 \%$ of SLE patients with grade I of the condition; in $80.0 \%$ with grade II, and in $85.7 \%$ of patients with grade III. The titer of elastase antibodies in SLE patients admitted to hospital was reliably higher than in the control group $(p<0.01)$. The highest elastase antibody titer was noted when the skin and joints are affected, and vasculopathy is present.

Conclusions: The regularities revealed by pathogenetic method can be accounted for by considerable B-clonal expansion in SLE patients as the condition progresses. From the point of view of immunology, hyperproduciton of elastin and elastase autoantibodies is noted, which results in autoimmune lesion of the ligamentous apparatus, joints, skin and vessels where this protein is naturally present.

Disclosure of Interest: None declared

DOI: 10.1136/annrheumdis-2018-eular.2668

\section{AB0527 S100 PROTEINS ARE NOVEL BIOMARKERS FOR THE EFFICACY OF HCQ TREATMENT TO SKIN LESION IN SYSTEMIC LUPUS ERYTHEMATOSUS}

R. Wakiya, K. Ueeda, T. Kameda, S. Nakashima, M. Izumkawa, H. Shimada, A. Kondo, M. Kato, T. Miyagi, N. Kadowaki, H. Dobashi. Department of internal medicine, Division of hematology, rheumatology and respiratory medicine, Kagawa University, Kagawa, Japan

Background: Systemic lupus erythematosus(SLE) is deeply associated with not only acquired immunity but also innate immunity throughout toll like receptors (TLRs) signalling. Among many TLRs, TLR7 and TLR9 were reported to be closely associated with IFN- $\alpha$ production which contributed the pathogenesis of SLE. On the other hand, several reports demonstrated that S100A8 and S100A9 proteins which was known as one of damage-associated molecular patterns (DAMPs), were associated with disease activity of lupus nephritis. These proteins were also shown to reflect the treatment response by immunosuppressive therapy for SLE. ${ }^{12}$ However, there is no report about the effect of hydroxychloroquine (HCQ) on S100A8 and S100A9 proteins expression.

Objectives: To find a new biomarker of treatment with $\mathrm{HCQ}$, we focused on expression of S100A8 and S100A9 proteins in SLE.

Methods: We enrolled all SLE patients treated with HCQ in the absence of additional immunosuppressive therapy more than 3 months in our institute from Jan 2016 to Dec 2017 Serum levels of S100A8 and S100A9 proteins were measured by ELISA(CircuLex ELISA Kit, MBL) at the screening, 3 months and 6 months after HCQ administration. Disease activity of SLE was measured using the SLENA-SLEDAI 2011 Cutaneous disease activity was evaluated by Cutaneous Lupus Erythematosus Disease Area and Severity Index (CLASI). Immunological activity was examined by the levels of complement (C3, C4, CH50), anti-dsDNA anti-body and counting blood cell.

Results: 61 patients were enrolled in this study. HCQ was administered 48 cases with usual dose(based on ideal weight), 15 cases with low dose than usual dose (table 1).

Abstract AB0527 - Table 1

\begin{tabular}{lccc}
\hline HCQ dose & $\begin{array}{c}\text { Usual dose } \\
(\mathrm{n}=46)\end{array}$ & $\begin{array}{c}\text { Low dose } \\
(\mathrm{n}=15)\end{array}$ & $\mathrm{P}$ \\
\hline Age, years, mean $\pm \mathrm{SD}$ & $40 \pm 12$ & $46 \pm 9$ & 0.07 \\
Female, no.(\%) & $43(93)$ & $13(87)$ & 0.40 \\
Disease duration, & $13 \pm 10$ & $11 \pm 8$ & 0.61 \\
years & & & \\
skin lesion & $40(87)$ & $14(93)$ & 0.48 \\
renal lesion & $19(41)$ & $0(0)$ & $<0.001$ \\
SLEDAl score & $3.9 \pm 2.2$ & $2.7 \pm 1.8$ & 0.06 \\
anti-dsDNA, IU/ml & $15 \pm 17$ & $9.9 \pm 3.1$ & 0.91 \\
C3, mg/dl & $79 \pm 24$ & $87 \pm 26$ & 0.32 \\
C4, mg/dl & $16.1 \pm 7.6$ & $19.2 \pm 9.2$ & 0.30 \\
CH50, U/ml & $33.6 \pm 9.6$ & $37.3 \pm 7.4$ & 0.30 \\
CLASl activity & $3.6 \pm 3.2$ & $2.6 \pm 2.8$ & 0.11 \\
Prednisone & $41(89)$ & $15(100)$ & 0.11 \\
Dose, mg/day & $5.6 \pm 3.1$ & $8.1 \pm 5.1$ & \\
\hline
\end{tabular}

CLASI was improved by the treatment with HCQ independent of HCQ dose. However, the effect of HCQ on SLENA-SLEDAI and immunological biomarker was shown in the patients treated with usual dose $\mathrm{HCQ}$, not shown in those treated with low dose HCQ. On the other hand, serum levels of S100A8 and S100A9 proteins were significantly elevated in SLE patients with renal lesion $(p=0.02)$. These proteins were significantly decreased by the treatment with $\mathrm{HCQ}$ regardless of the $\mathrm{HCQ}$ dose $(\mathrm{p}<0.0001)$. The changes of serum S100A8 and S100A9 proteins during HCQ treatment(for 3 months) were significantly associated with changes of CLASI(figure 1).

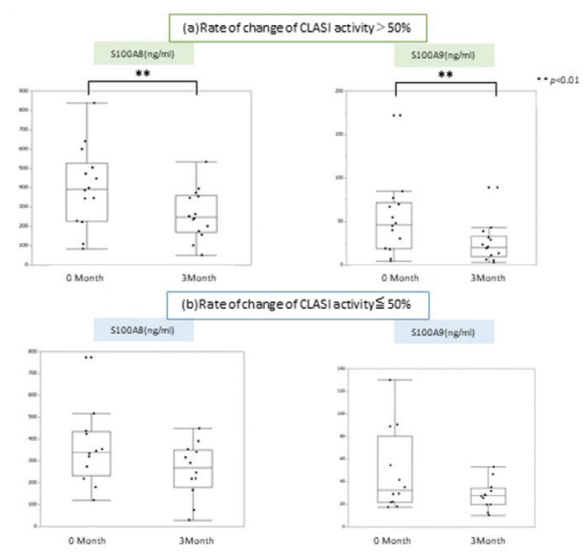

Abstract AB0527 - Figure 1. S100A8 and S100A9 proteins associated with CLASI score. Compared with SLE patients of $50 \%$ and less rate of change of CLASI activity, those of more than $50 \%$ rate of change of CLASI activity significantly decreased serum levels of S100A8 and S100A9 proteins after administration of HCQ. There were no SLE patients whose skin lesion got worse during HCQ treatment in this study.

Conclusions: HCQ reduced the expression of serum S100A8 and S100A9 pro teins, which reflected SLE disease activity especially in skin lesion. The measurement of S100A8 and S100A9 proteins is novel predictive biomarker for the efficacy of $\mathrm{HCQ}$ treatment on skin lesion in SLE patients.

\section{REFERENCES:}

[1] Tyden $\mathrm{H}$, et al. Pro-inflammatory S100 proteins are associated with glomerulonephritis and anti-dsDNA antibodies in systemic lupus erythematosus. Lupus 2017;(26):139-149.

[2] Tantivitayakul $P$, et al. Elevated expressions of myeloid-related proteins-8 and -14 are danger biomarkers for lupus nephritis. Lupus 2016;(25):38-45

Disclosure of Interest: None declared

DOI: 10.1136/annrheumdis-2018-eular.2109

\section{AB0528 CONCOMITANT MEDICATION IN SYSTEMIC LUPUS ERYTHEMATOUS (SLE) PATIENTS TREATED WITH BELIMUMAB IN CLINICAL PRACTICE SETTINGS: RESULTS FROM THE OBSERVE STUDY IN SWITZERLAND}

J. von Kempis ${ }^{1}$, S. Dütsch ${ }^{2}$, N. Reuschling ${ }^{1,3}$, D. Schaer ${ }^{4}$, F. Vallelian ${ }^{4}$, R. Villiger ${ }^{5}$, P.M. Villiger ${ }^{5}$, R.B. Mueller ${ }^{1} .{ }^{1}$ Department of Rheumatology, Kantonsspital St. Gallen, St. Gallen; ${ }^{2}$ GlaxoSmithKline AG, Münchenbuchsee; ${ }^{3}$ Division of Rheumatology, Hirslanden, Basel; ${ }^{4}$ Universitä Hospital Zürich, Zürich; ${ }^{5}$ Department of Rheumatology, Inselspital Bern, Bern, Switzerland

Background: Systemic lupus erythematosus (SLE) is a complex and potentially severe autoimmune disease. Belimumab is the latest drug, and the first biologic compound, that was registered for treatment of SLE. There is limited information on safety and effectiveness of belimumab and its effects on the use of concomitant medication outside of randomised controlled trials.

Objectives: To describe the overall patterns of SLE care, outcomes and concomitant medication among belimumab users in Switzerland.

Methods: OBSErve Switzerland (GSK 201232) was a retrospective, multi-centre observational cohort study collecting data on the use of belimumab therapy in routine care of SLE Patients in Switzerland. SLE patients were included who had started therapy with $10 \mathrm{mg} / \mathrm{kg}$ belimumab/4 weeks at least six months before documentation. All patients were included regardless of treatment discontinuation during the study period. All statistical analyses were descriptive for both categorical and quantitative data.

Results: 53 SLE patients with belimumab as part of their routine treatment were analysed for this study. $81 \%$ of the patients were female, the mean age was 46.7 years and the mean BMI was $25.4 \mathrm{~kg} / \mathrm{m}^{2}$. The reasons to initiate belimumab were ineffective previous treatment $(66.0 \%)$, worsening of patient condition (28.3\%), and/or the intent to decrease glucocorticosteroid (GC) dose (47.2\%). 